\title{
COMPARISON OF THE EFFICACY OF TWO DISINFECTANTS FOR CONTROLLING GRAM-POSITIVE BACTERIA ON THERMOPLASTIC RETAINERS IN DENTAL PLAQUES
}

\author{
CITRA PARAMITA, MIESJE K. PURWANEGARA*, FARUK HOESIN
}

Department of Orthodontics, University of Indonesia, Jakarta 13410, Indonesia. Email: miesjekar@gmail.com

Received 12 October 2018, Revised and Accepted 27 February 2019

\begin{abstract}
Objective: Thermoplastic retainers are believed to be able to change the ecosystem for the oral cavity microflora. To prevent oral tissue damage, it is vital that retainers are subjected to appropriate cleaning techniques. This study compared the effectiveness of two disinfectants in cleaning
\end{abstract} thermoplastic retainers against Gram-positive bacteria in the dental plaque layer.

Methods: The two disinfectants used in this study were Polident and $0.1 \%$ chlorhexidine gluconate. We performed laboratory studies on Gramnegative bacteria using a single-blind setup, with three groups of subjects, each with 13 participants.

Results: The results showed that there was a significant reduction in the number of Gram-positive bacterial colonies in the dental plaque layer on retainers cleaned with Polident compared with the control, whereas cleaning the retainer with $0.1 \%$ chlorhexidine gluconate showed no significant difference in the number of Gram-positive bacteria compared with the control.

Conclusion: We conclude that there is a significant difference in the number of Gram-positive bacteria on the teeth before and after insertion of a thermoplastic retainer in Polident solution, whereas immersion in Minosep did not reduce bacterial numbers compared with that in the control.

Keywords: Thermoplastic retainer, Bacterial colony count, Chlorhexidine gluconate, Dental plaque.

(C) 2019 The Authors. Published by Innovare Academic Sciences Pvt Ltd. This is an open access article under the CC BY license (http://creativecommons. org/licenses/by/4. 0/) DOI: http://dx.doi.org/10.22159/ijap.2019.v11s1.179

\section{INTRODUCTION}

Among the treatment goals in orthodontics are the maintenance of occlusal stability after correction and the correct position of the teeth after active orthodontic treatment [1,2]. A retainer is used to maintain the stability and to prevent relapse. A retainer can be removable or fixed. The types of removable retainer are the Hawley and thermoplastic retainers, whereas fixed retainers include bonded lingual retainers [1,2].

Currently, various types of retainers have been developed. Removable retainers are the most frequently used. According to Proffit (2007), currently, thermoplastic retainers are more commonly used because they are not only easy to use but also have good esthetic appearance. Thermoplastic retainers are made of clear polyester which covers the entire palatal, labial, and lingual side of the teeth and gingiva [3].

Although the main purpose of a thermoplastic retainer is to maintain occlusal stability, it can also affect oral tissues. A thermoplastic retainer can act as a medium for plaque retention, increasing the risk of oral tissue damage. Therefore, proper cleaning techniques are necessary to prevent the buildup of plaque on these retainers [3].

Some retainer cleaning techniques using disinfectant solutions have been developed to date. Based on the research by Peixoto et al. [4], chlorhexidine was shown to be very effective in cleaning an acrylic base, which is often used in removable retainers. It was also effective in reducing the number of colonies of Streptococcus mutans compared with the control group.

Lessa et al. compared the efficacy of disinfectant constituents on retainers; they compared the efficacy of $0.12 \%$ Periogard solution (active ingredient, chlorhexidine gluconate) and Cepacol $(0.05 \%$ cetylpyridinium chloride solution) with sterile water as the control. The results of the study showed that Periogard was the most effective in reducing the number of $S$. mutans colonies and development of biofilm on the acrylic layer of the retainer, while Cepacol also proved to be effective compared with the control [5].

This study aimed to describe the evaluation of cleaning techniques using disinfectant solutions on thermoplastic retainers. The aim of this research was to compare the efficacy of two disinfectants $0.1 \%$ chlorhexidine digluconate (Minosep) and Polident (containing sodium perborate monohydrate, sodium polyphosphate, potassium peroxymonosulfate, and ethylenediaminetetraacetic acid), which are commonly used for cleaning thermoplastic retainers, against dental plaque in the form of Gram-positive bacterial colonies in the oral cavity. These disinfectant solutions are used to prevent caries lesions when wearing thermoplastic retainers so that the good occlusal stability can be maintained and the retainer used following orthodontic treatment remains effective.

\section{METHODS}

The research used a randomized clinical trial study design. The research was conducted in the Orthodontic Clinic of Dental Hospital, Faculty of Dentistry, University of Indonesia. The colony count assays were performed in the Microbiology Laboratory, Faculty of Dentistry, Universitas Indonesia. Sample collection was carried out by taking a swab from the tooth surface of each subject at certain time points before and after using a retainer and after using a retainer which had been cleaned by disinfectants.

The subjects of this research were students of the Faculty of Dentistry, University of Indonesia, who met the following criteria for inclusion: 18-38 years of age, good oral hygiene, healthy periodontal tissue condition, absence of caries, not consuming antibiotics in the preceding 2 weeks, no systemic disease, not pregnant, not fitted with prosthodontic appliances, nonsmoker, and good dentition alignment. The criteria of exclusion were poor oral hygiene, history of systemic disease, pregnancy, and consumption of antibiotics. 
The variable used in this research was the number of colonies of Grampositive bacteria in the three sample groups, with each group consisting of 13 randomly selected subjects. The subjects of the first group immersed their retainers in Polident solution, those of the second group immersed their retainers in $0.1 \%$ chlorhexidine gluconate solution, and those of the third group immersed their retainers in aquades (control) [6,7].

Each subject wore a retainer all the time, except while eating, for 15 days. Before wearing the retainer, subjects were instructed about maintaining oral hygiene at home. On the first visit, a thermoplastic retainer was fitted in each subject. After $24 \mathrm{~h}$, an early swab was collected on the on the entire first molar from the left to the right first molar. The swab was collected from the labial side of the teeth with a sterile cotton swab, followed by microbial analysis. The Polident group immersed their retainer for approximately $5 \mathrm{~min}$ in $120-\mathrm{ml}$ mineral water in which one Polident tablet was dissolved. This process was carried out each day for 15 days. The Minosep group immersed their retainers for $10 \mathrm{~min}$ in 60 -ml Minosep solution once every 4 days for 15 days. The control group immersed their retainers in distilled water for approximately 5 min every day for 15 days. For all the three groups, the retainer was immersed in a standard container provided for each subject. On day 15, a swab was collected from each subject, which was then subjected to further microbial analysis.

The bacteria on the swab were then cultured in TYSB20 medium. The results were obtained by counting the number of colonies two times and calculating the average. This research used a single-blind technique to help reduce any possible bias; the subjects did not know the type of disinfectant given [7].

\section{RESULTS}

The initial number of subjects was 39 (three groups, 13 replicates per group), but the final sample size was 35 because some subjects consumed antibiotics, forgot to treat their retainer, or were not present when the immersion/swabbing processes were conducted. This resulted in a reduction of the strength of this research from $90 \%$ to $85 \%$; however, it was still acceptable because it was within the specified limits.

The bacteria in the swab were allowed to multiply by incubation to obtain more accurate estimates of bacterial density. Before the number of colonies per plate was counted, each colony on the plate was picked and stained for Gram-positive bacteria. The Gram-positive bacterial colonies were found to be round, small, and golden yellow, with a clear border, and were not obvious to the naked eye.

Interobserver test was performed by selecting three samples from each group and at each time point. A paired $t$-test was performed because the data were normally distributed. The results obtained at the initial counting had $p$ value of 0.89 and those at the final counting had $p$ values of 0.70 , suggesting that there was no statistical difference between the researchers' observations ( $p>0.05$ was considered statistically significant) (Tables 1-3).

After Gram-positive bacterial colonies were counted before and after treatment in each group, a distribution test was conducted. Based on its results, it was concluded that the data distribution approximated to

Table 1: Characteristics of research subjects

\begin{tabular}{llll}
\hline Group & Age (years) & Sex & n \\
\hline A & $18-27$ & Female: 11 & 11 \\
B & $20-28$ & Male: 0 & \\
& & Female: 10 & 12 \\
C & $19-27$ & Male: 2 & \\
& & Female: 10 & 12 \\
& & Male: 2 & \\
\hline
\end{tabular}

normality. Group A (treatment with Polident) had a maximum count of Gram-positive bacteria of $1050 \mathrm{cfu} / \mathrm{mL}$ and minimum of $255 \mathrm{cfu} / \mathrm{mL}$, with a mean count of $678.36 \mathrm{cfu} / \mathrm{mL}$. Group B (treatment with Minosep) had a maximum count of $1020 \mathrm{cfu} / \mathrm{mL}$ and minimum of $44 \mathrm{cfu} / \mathrm{mL}$, with a mean count of $487.75 \mathrm{cfu} / \mathrm{mL}$. Group C (control) had a maximum count of $1050 \mathrm{cfu} / \mathrm{mL}$ and minimum of $18 \mathrm{cfu} / \mathrm{mL}$, with a mean count of $401.27 \mathrm{cfu} / \mathrm{mL}$ (Fig. 1). The number of Gram-positive bacterial colonies after treatment approximated to a normal distribution. Group A had a maximum count of $624 \mathrm{cfu} / \mathrm{mL}$ and minimum of $223 \mathrm{cfu} / \mathrm{mL}$, with a mean count of $386.54 \mathrm{cfu} / \mathrm{mL}$. Group B had a maximum count of $974 \mathrm{cfu} / \mathrm{mL}$ and minimum of $50 \mathrm{cfu} / \mathrm{mL}$, with a mean count of $466.83 \mathrm{cfu} / \mathrm{mL}$. Group C had a maximum count of $748 \mathrm{cfu} / \mathrm{mL}$ and minimum of $20 \mathrm{cfu} / \mathrm{mL}$, with a mean count of $383.81 \mathrm{cfu} / \mathrm{mL}$. Normality test on the count difference approximated to a normal distribution. Group A had a maximum count of $546 \mathrm{cfu} / \mathrm{mL}$ and minimum of $25 \mathrm{cfu} / \mathrm{mL}$, with a mean count of $291.8 \mathrm{cfu} / \mathrm{mL}$. Group B had a maximum count of $47 \mathrm{cfu} / \mathrm{mL}$ and minimum of $-16 \mathrm{cfu} / \mathrm{mL}$, with a mean count of

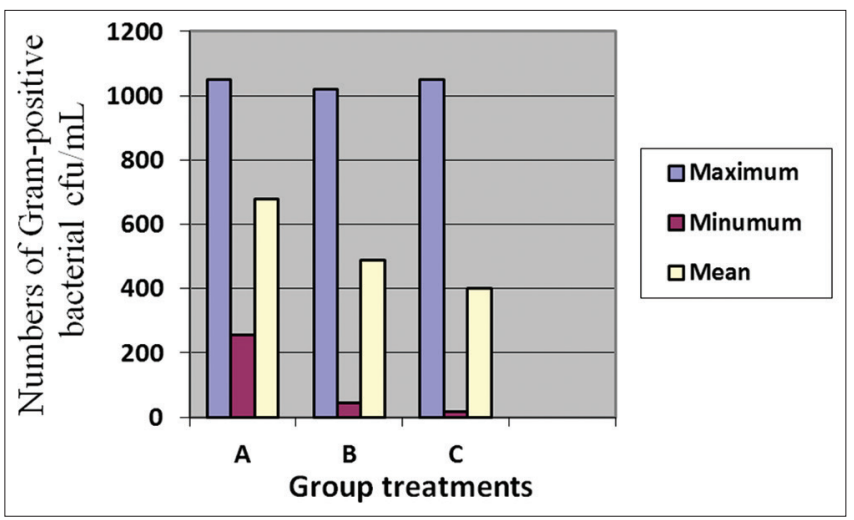

Fig. 1: Numbers of Gram-positive bacterial colonies before treatment in (A) Polident, (B) Minosep, and (C) control groups

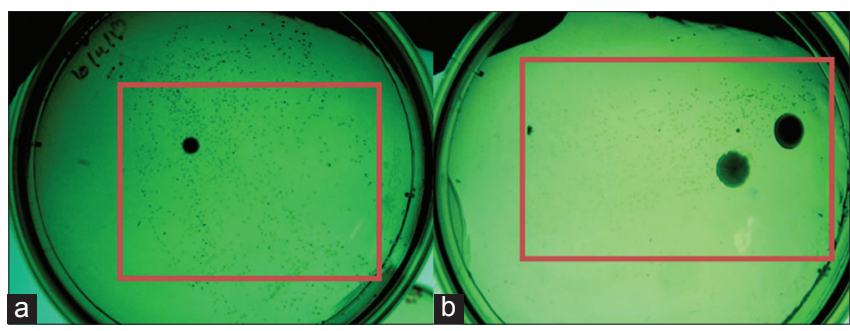

Fig. 2: Results of Gram-positive bacterial culture on agarose medium from swabs from a retainer before (a) and after

(b) immersion in Polident. The colonies are round, small, golden yellow, and not prominent. The larger colonies are of fungi

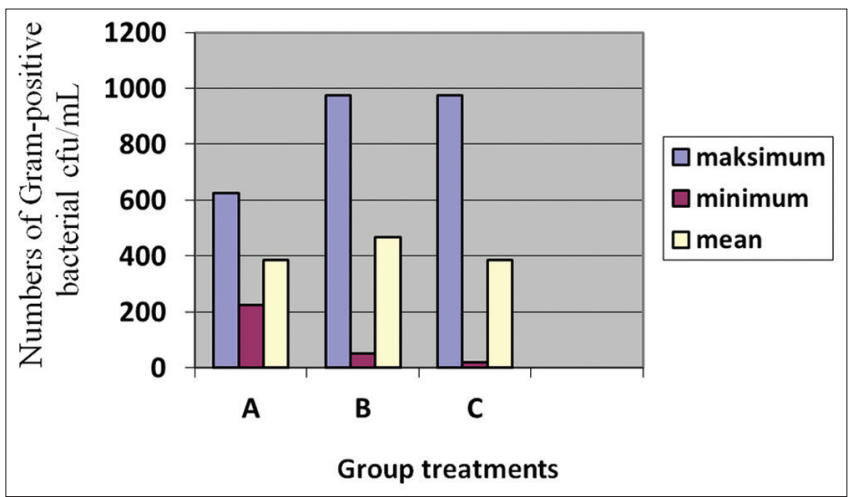

Fig. 3: Numbers of Gram-positive bacterial colonies after treatment of the retainer with Polident (A), Minosep (B), and control (C) 
Table 2: Interobserver calculation data of each group before and after treatment

\begin{tabular}{llllll}
\hline Group & T1-1 & T1-2 & t-test (T1-1 and T1-2) & T2-1 & T2-2 \\
\hline A & 976 & 943 & $\mathrm{p}=0.89$ & 540 & 561 \\
A & 1068 & 1050 & & 750 & 768 \\
A & 1140 & 2153 & & 994 & 720 \\
B & 1350 & $1333=0.70$ & 1254 & 1320 \\
B & 2127 & 621 & & 563 & 554 \\
B & 789 & 752 & & 940 & 2164 \\
C & 1430 & 1460 & & 1335 & 2076 \\
C & 980 & 2144 & & 964 & 974 \\
C & 959 & 680 & & 920 & 2039 \\
\hline
\end{tabular}

Table 3: Results of normality test

\begin{tabular}{lll}
\hline Group & Before treatment & After treatment \\
\hline A & 0.537 & 0.556 \\
B & 0.116 & 0.092 \\
C & 0.522 & 0.136 \\
\hline$P<0.05$ & &
\end{tabular}

Table 4: Post Hoc analysis results between groups

\begin{tabular}{ll}
\hline Group & p value* \\
\hline A-B & $0.00^{*}$ \\
A-C & $0.00^{*}$ \\
B and C & 0.89 \\
\hline
\end{tabular}

Description: A group: Polident tablet B group: Minosep C group: Aquades *p value: 0.05

$19.2 \mathrm{cfu} / \mathrm{mL}$. Group C had a maximum count of $75 \mathrm{cfu} / \mathrm{mL}$ and minimum of $-22 \mathrm{cfu} / \mathrm{mL}$, with a mean count of $7.45 \mathrm{cfu} / \mathrm{mL}$ (Figs. 2-6).

As the data approximated to a normal distribution, a paired $t$-test was used to evaluate the changes in the numbers of Gram-positive bacterial colonies before and after treatment in each group. Based on the results of $t$-test analysis, it was found that there were significant differences in the numbers of colonies of Gram-positive bacteria before and after treatment of the thermoplastic retainer with Polident solution. Furthermore, there were no differences in the numbers of colonies of Gram-positive bacteria on the teeth before and after treatment of the thermoplastic retainer with Minosep and control solutions.

One-way ANOVA revealed significant differences $(n=2 ; p<0.001)$ between the three treatment groups. Post hoc analysis using the Tukey test (or Duncan's multiple range test) was carried out to identify the differences among the treatment methods (Table 4). There was significantly more $(\mathrm{p}<0.05)$ number of Gram-positive bacteria on the teeth after treatment of the thermoplastic retainer with Minosep solution than with Polident solution. Furthermore, there was significantly $(\mathrm{p}<0.05)$ more number of bacterial colonies on the teeth after treatment of the retainer with Polident solution, but there was no significant difference in the number of colonies between Minosep- and water-treated retainers $(\mathrm{p}=0.89)$.

\section{DISCUSSION}

This research was designed to determine the differences in the efficacies of two commercially available disinfectant solutions in cleaning thermoplastic retainers to help reduce the number of Grampositive bacteria attached to the surface of the teeth.

The two cleaning methods for thermoplastic retainers in this study used chemical disinfectants. The most commonly used cleaning solution is Minosep because it is able to eliminate biofilms, has antimicrobial components, and is considered sufficiently effective to prevent the formation of white spot, caries, and periodontal diseases.

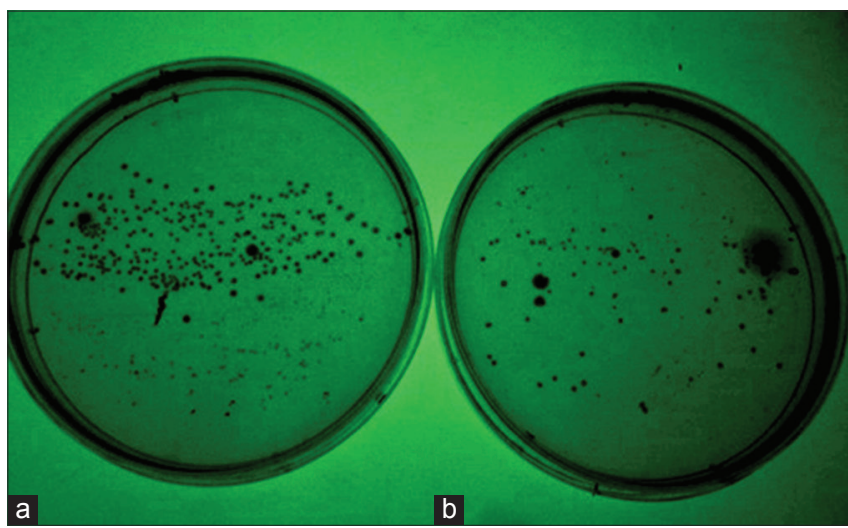

Fig. 4: Bacterial cultures from a retainer swab on agarose medium before (a) and after (b) treatment with Minosep

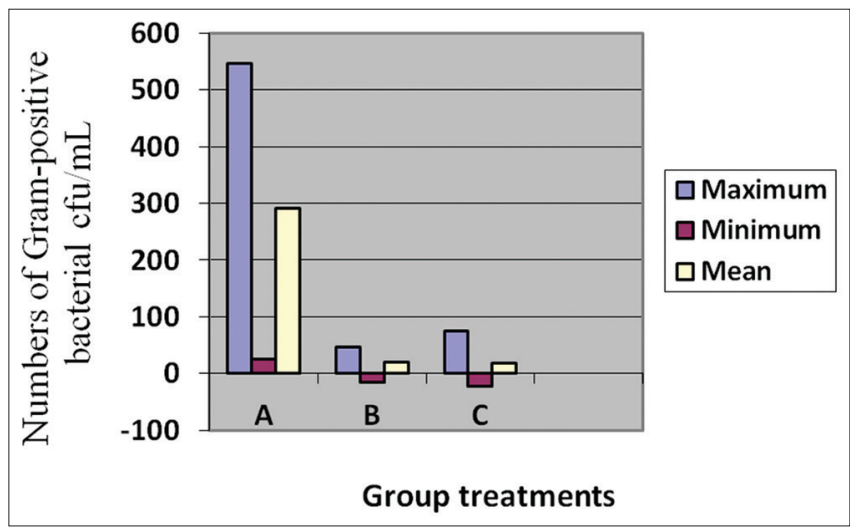

Fig. 5: Differences in numbers of Gram-positive bacterial colonies before and after treatment with Polident (A), Minosep (B), and control (C)

Polident solution is often used to clean the acrylic on dentures. Sodium perborate monohydrate and potassium peroxymonosulfate in Polident are bioactive chemicals which can generate hydrogen peroxide, which is an antimicrobial, causes bleaching, and inhibits the growth of bacteria. There was no significant difference in the number of Grampositive bacteria on the teeth after immersion of the thermoplastic retainer in Minosep and control solutions ( $p>0.05)$. According to some studies, Minosep is an effective solution for eliminating a biofilm and killing Gram-positive bacteria in the oral cavity. Chlorhexidine helps to eliminate a biofilm and prevent bacterial attachment (e.g., of Candida albicans) to the retainer [8].

The results of this study were contradictory to those of Peixoto et al., which showed a significant decline in the number of Gram-positive bacteria on the retainer after immersion in $0.1 \%$ chlorhexidine gluconate [4]. This difference may be attributed to the fact that direct application of chlorhexidine, such as by rinsing and irrigation in the 


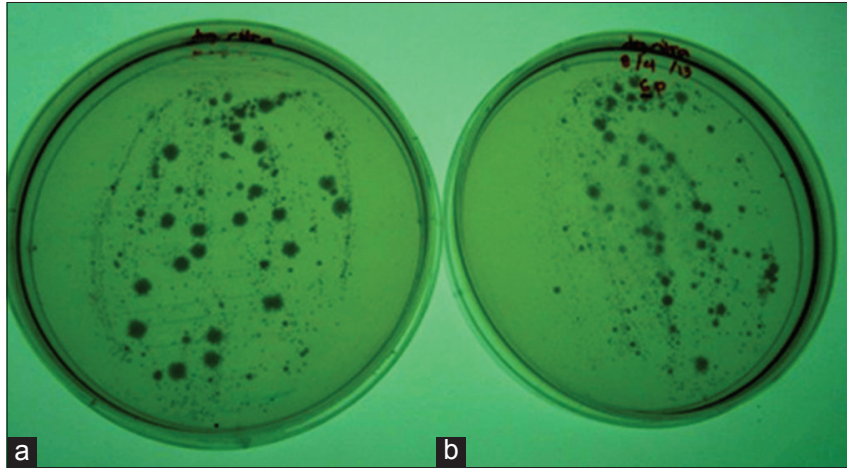

Fig. 6: Bacterial colonies from a retainer swab on agarose medium before (a) and after (b) immersion in water

mouth, is more effective in reducing bacterial counts and biofilm attachment, thereby reducing plaque accumulation.

Based on the results of the paired $t$-test analysis, there was a significant decrease in the number of Gram-positive bacteria on the teeth after the thermoplastic retainer was treated with Polident solution $(\mathrm{p}<0.001)$. These findings were in agreement with those of Senocak et al. [9] who reported that Polident solution produces hydrogen peroxide, which may inhibit the growth of bacteria and destroy the food remnants. Sodium perborate contained in Polident tablets dissolves in water to produce hydrogen peroxide. Peroxide produced is pure bond and not derivative chemical bond oxidation results. The reaction is as follows:

$$
\left.\mathrm{NaBO}_{2}(\mathrm{OH})_{2} \times \mathrm{H}_{2} \mathrm{O}\right]_{2} \leftrightarrows 2 \mathrm{NaBO}_{2}+2 \mathrm{H}_{2} \mathrm{O}_{2}+6 \mathrm{H}_{2} \mathrm{O}
$$

Sodium perborate sodium metaborate + hydrogen peroxide + water

This cleaning solution can be used on its own or combined with a mechanical cleaning method. Polident tablets produce hydrogen peroxide, which has antiseptic effects.

One-way ANOVA revealed significantly more number of Gram-positive bacteria on the teeth after the thermoplastic retainer was treated with Minosep than with Polident solution. This result was in accordance with that of Lee et al. [10] who compared the effectiveness of six cleaning techniques for dentures made of acrylic resin. They showed that immersion in Polident solution had a greater effect in eliminating biofilms and $C$. albicans colonies than that by immersion in $0.2 \%$ chlorhexidine (twice the concentration of Minosep). No significant difference in the number of Gram-positive bacteria was observed when the retainers were immersed in Minosep or water. This result was contrary to the result of Peixoto [4]. This discrepancy may have resulted because the direct application of chlorhexidine is considered to be more effective. Other factors that may have affected the results of this study include the immersion time and instructions given to the subjects regarding the cleaning technique. Immersion in Minosep solution was carried out every 4 days for $10 \mathrm{~min}$, whereas that for Polident solution was carried out every day for $5 \mathrm{~min}$. Although the immersion period for Minosep was longer than that for Polident, it was still not effective in reducing the numbers of Gram-positive bacteria on the teeth surface.

Contamination during bacterial culture and medium storage could also have affected the results of the current study. Despite sterilization, contamination may occur due to air exposure or tools used. The medium before incubation is very vulnerable to contamination because of the presence of stored media used by other researchers. Furthermore, in some cases, sterilization is performed with only $70 \%(\mathrm{v} / \mathrm{v})$ ethanol.
Therefore, in reducing the bias during the study, agarose medium was cultured through the selection process over the help of oral biology laboratory officer. When there was high contamination on the agarose medium, the culturing was repeated.

Immersion of a thermoplastic retainer in Polident solution significantly reduced the number of Gram-positive bacteria on the teeth compared with the control solution. Citric acid is one of the active ingredients of Polident tablets. It is an acidic disinfectant, which can damage bacterial polypeptides as well as reduce the environmental $\mathrm{pH}$ which negatively affects bacterial growth. Its antimicrobial nature is $\mathrm{pH}$ dependent. Furthermore, Polident contains sodium carbonate, which is an alkaline compound that affects the cell walls of microorganisms. Sodium perborate monohydrate can produce hydrogen peroxide, which at concentrations of $5 \%-20 \%$ can be bactericidal. Alkaline peroxide can damage the organic substances which adhere to the denture. On dissolving in water, the peroxide is converted to alkaline hydrogen peroxide, which then decomposes, releases oxygen bubbles which simultaneously exert a mechanical action, and eliminates biofilm layers from the dentures. Oxidizing agents help remove stains and commonly have antibacterial action [9].

\section{CONCLUSION}

Based on the results of the research, it can be concluded that there is a significant difference in the number of Gram-positive bacteria on the teeth before and after insertion of a thermoplastic retainer in Polident solution, whereas immersion in Minosep did not reduce bacterial numbers compared with that in the control.

\section{CONFLICTS OF INTERESTS}

The authors declare that there is no conflicts of interests.

\section{REFERENCES}

1. Profitt WR, Fields HW Jr., Sarver D. Contemporary Orthodontics. $4^{\text {th }}$ ed. Missouri: Mosby; 2007. p. 617-9.

2. Bishara SE. Text Book of Orthodontics. Philadelphia, PA: W.B Saunders; 2001.

3. Pfeffer L. Bacterial Adherence of Streptococcus mutans and Lactobacillus acidophilus on Poly-Methyl Methacrylate and Thermoplastix Polypropene Used in Othodontic Retention. Las Vegas: Master of Oral Biology Department of Orthodontics, University of Nevada; 2011.

4. Peixoto IT, Enoki C, Ito IY, Matsumoto MA, Nelson-Filho P. Evaluation of home disinfection protocols for acrylic baseplates of removable orthodontic appliances: A randomized clinical investigation. Am J Orthod Dentofacial Orthop 2011;140:51-7.

5. da Silva FC, Kimpara ET, Mancini MN, Balducci I, Jorge AO, KogaIto CY, et al. Effectiveness of six different disinfectants on removing five microbial species and effects on the topographic characteristics of acrylic resin. J Prosthodont 2008;17:627-33.

6. Lara-Carrillo E, Montiel-Bastida NM, Sánchez-Pérez L, AlanísTavira J. Effect of orthodontic treatment on saliva, plaque and the levels of Streptococcus mutans and Lactobacillus. Med Oral Patol Oral Cir Bucal 2010;15:e924-9.

7. Murdoch DA. Gram-positive anaerobic cocci. Clin Microbiol Rev 1998;11:81-120.

8. Sato S, Pedrazzi V, Guimarães Lara EH, Panzeri H, Ferreira de Albuquerque R Jr., Ito IY, et al. Antimicrobial spray for toothbrush disinfection: An in vivo evaluation. Quintessence Int 2005;36:812-6.

9. Senocak E, Tazkensenligil Y, Tumer F, Kazaz C. Reaction of alkenes with sodium perborate and sodium chloride. Turk J Chem 2005;29:679-85

10. Lee H, Li C, Chang HW, Yang YH, Wu JH. Effect of different denture cleaning methods to remove Candida albicans from acrylic resin denture based material. J Dent Sci 2011;6:216-20. 